\title{
Evaluation and Optimization of Inventory Control Systems in Small and Medium Scale Industries
}

\section{Chinwuko Emmanuel Chuka ${ }^{1}$, Nwakoby John Oguejiofor ${ }^{2}$, Asowo Clement Sunday ${ }^{3}$}

Industrial and Production Engineering, Nnamdi Azikiwe University, Awka, Anambra state, Nigeria ${ }^{123}$

\begin{abstract}
This work provides an overview of inventory with the intention of using decision model to analyze and evaluate inventory in small and medium scale industries with the aim of optimizing the inventory system inEvepon Industries Limited, Enugu state, Nigeria. Data were collected from the case company and the research method used is the application of the inventory control models. Based on the models applied, the aforementioned company's analysis shows that the economic ordering quantity of the raw materials which are products 2, 3, 4, 5, 6 and 7 have 2700.81, 286.84, 772.77, 61.4, 6.43 and 7.21 respectively. Products 2, 3, 4, 5, 6 and 7 have reordering point of $675.2,71.71,193.19,15.35,1.61$ and 1.8 respectively while the products $2,3,4$, 5, 6 and 7 have lead time of 4.12, 13.13, 5.9, 28.11, 36.82 and 49.54 respectively. The results develop standards for the case company and similar case studies for its use and applicability in other to eliminate and/or to reduce the inventory control and production planning problems. This technique will help manufacturing industries in general and the case study company to reduce running cost, effective utilization of the inventory control system and appraisal of the production planning system.
\end{abstract}

Keywords: Inventory control, Economic ordering quantity, Economic Production quantity, reordering point, Lead time, Production rate, setup cost, holding cost and unit cost

\section{INTRODUCTION OF THE STUDY}

Inventory refers to the goods and materials that an organization, company, or business holds to support production, support activities and for sale or customer service.Inventory Control is the supervision of supply, storage and accessibility of items in order to ensure an adequate supply without excessive oversupply.The principal goal of inventory management involves having to balance the conflicting economics of not ready to hold too much stock. Thereby having to tie up capital so as to guide against the incurring of costs such as storage, spoilage, pilferage and obsolescence and, the desire to make items or goods available when and where required (quality and quantity wise) so as to avert the cost of not meeting such requirement (Adeyemi\& Salami, 2012). Inventory problems of too great or too small quantities on hand can cause business failures. If an item is not stocked when the customer thinks it should be the retailer loses a customer not only on that item but also on many other items in the future. The conclusion one might draw is that effective inventory management can make a significant contribution to a business profit as well as increase its return on total assets. It is thus the management of this economics of stockholding, that is appropriately being refers to as inventory management. The reason for greater attention to inventory management is that this figure, for many firms, is the largest item appearing on the asset side of the balance sheet. Essentially, inventory management, within the context of the foregoing features involves planning and control.

The planning aspect involves looking ahead in terms of the determination in advance:

(i) What quantity of items to order; and (ii) How often (periodicity) do we order for them to maintain the overall stock coordination in an economically efficient way? The control aspect, which is often described as stock control involves following the procedure, set up at the planning stage to achieve the above objective. This may include monitoring stock levels periodically or continuously and deciding what to do on the basis of information that is gathered and adequately processed. Effort must be made by the management of any organization to strike an optimum investment in inventory since it costs much money to tie down capital in excess inventory.

Financial analysts have sounded enough warning on the danger expose to the long run profitability as well as continuity of business concern when its inventories are left unmanaged (Adeyemi\& Salami 2012). First, a company, which neglects it management of inventory, runs the risk of production bottlenecks and subsequently unable to maintain the minimum investment it requires to maximized 
profit. Second, inventories that are inefficiently managed may apart from affecting sales create an irreparable loss in market for companies operating in highly competitive industry.

Invariably, a company must neither keep excess inventories to avoid an unnecessary tying down of funds as well as loss in fund due to pilferage, spoilage and obsolescence nor maintain too low inventories so as to meet production and sales demand as at when needed.

However, in recent time, attention was focused on the development of suitable mathematical tools and approaches designed to aid the decision-maker in setting optimum inventory levels. The Economic order quantity model (EOQ) and Reorder Point (ROP) has thus been developed to take care of the weaknesses emanating from the traditional methods of inventory control and valuation, which to some extent has proved useful in optimizing resources and thus, minimizing associated cost.

Analysis of an Economic order quantity could assist in deciding what would be the best optimal order quantity at the company's lowest price and the reorder point which will advise when to place an order for specific products based on their historical demand. The reorder point also allows sufficient stock at hand to satisfy demand while the next order arrives due to the lead time. However, understanding demand and the ability to accurately predict is imperative for big retailers companies.

\section{RESEARCH OBJECTIVE}

This study achieved the following objectives:

Analyzing an Economic Order Quantity and Re-Order point model, thereby aiding Eveponindustry limited to be able to determine the order quantity and re-order point for each of their products.

Minimizing inventory cost as well as stockout issues, which is the major problem most companies are facing today.

\section{INVENTORY MANAGEMENT}

Inventory Management is the overseeing and controlling of the ordering, storage and use of components that a company will use in the production of the items it will sell as well as the overseeing and controlling of quantities of finished products for sale.

There is need for installation of a proper inventory control model in any business organization. According to Kotler (2000), inventory management refers to all the activities involved in developing and managing the inventory levels of raw materials, semi-finished materials (work-in-progress) and finished goods so that adequate supplies are available and the costs of over or under stocks are low. Rosenblatt (1977) explained that the cost of maintaining inventory is included in the final price paid by the consumer.

Small and Medium Scale Enterprises as a concept defines universal definition both among academics and practitioners. It has been both relative and dynamic, varying from country to country, even over time and among industries. The development of small and medium scale industries is very important to the growth of a nation especially a developing country. Ogunleye (2000) stated that small and medium scale enterprises are particularly relevant in creating employment opportunities, mitigating rural urban drift, producing specialized items in small quantities to meet diverse needs, mobilization of local resources as well as stimulation of technological development and innovation. This view was also expressed by Edwardson (1989). (Loveman and Sengenberger, 1992) acknowledged the superiority of small-scale industrialization strategy in promoting economic growth. As a matter of fact, a positive correlation between the emergence of an active small-scale industrial sector and the commencement of rapid economic growth and development can always be established. A practical illustration is the recent transformation of some South East Asian economies from rudimentary states to high-industrialized ones in the second half of the last century. To achieve the desired contribution of SMEs to the industrial growth of a nation, the management of inventory in these organisations is of utmost importance. Inventories are goods that are kept to meet future demand and to ensure production continuity. It is a very important asset in any business organisation. The management of this vital asset is very important for the efficiency, effectiveness and profitability of the business. Forgionne(1986);Adeyemi and Salami (2012) claimed that the astute manager who understands the virtues of each of the component of inventory could use them selectively to implement corporate strategy in the market place. An organisation can strategically build up inventory for market promotion and also to stabilise production schedule. Inventory management is crucial to organisation 
success since holding too little or too much stock has negative effect on the organisation's performance. The problem of inventory has continued to receive much attention in most businesses. Inventory levels of raw materials, semi-finished and finished goods need to be effectively managed to control the cost of inventory Kotler, (2002). It is common to find the balance sheet of an average company having inventory running to $60 \%$ of its current assets as capital tied down Pandey (2005). Apart from this, much has to be expended additionally to keep it useful. To keep production going, some level of inventory is desirable. Despite the marvel of computer, automation and scientific management, the production process and marketing activities cannot still avoid the need to have inventories. Jegede, (1992) stated that the necessity of keeping stock arises because of the time lapse between purchasing, production and eventual sale to customers. The major concern is how inventory can be controlled to minimize waste and cost. Thus an efficient inventory policy is always an important requirement for the successful management of manufacturing and distributing enterprises. Inventory planning is a major tool of capacity planning and every organization must ensure effective inventory planning to enhance efficient and effective capacity utilization. Orlicky (1975) identified the main purpose of a basic material requirement planning as to control inventory level, assign operating priorities for items, and plan capacity to load the production system as well as to order the right part, order the right quantity and order at the right time. In their contribution to importance of inventory Chase and Aquiliano (1985) mentioned that the objectives of inventory management under the material requirement planning system are to improve customers' service to minimize inventory investment, and to maximize production operating efficiency. Garrison and Noreen (2000) opined that the selection of the right level of inventories involves balancing three groups of costs. These costs are: inventory ordering cost, inventory carrying costs, the cost of not carrying sufficient inventory and opportunity cost. Plane (1994) observed that if inventory levels are low, the cost associated with keeping inventory on hand is small, but orders are place more frequently to replenish items, to avoid running out of stock always.. If inventory levels are very high, maintaining these inventories is expensive but there may be benefits from obtaining larger lot sizes from suppliers. Schreibfeder (2001) stressed that cost of carrying is a critical factor in deciding what products to stock and when to re-order them as well as the best quantity to order. However, companies and organization often use an imprecise 'rule of thumb' to estimate their cost of carrying inventory and the resultant effect is bad inventory management. Just in time inventory (JIT) is the modern concept in inventory management aimed at reducing inventory costs. With just in time inventory, the exact amounts of good items arrive at the moment they are needed. Adam and European Journal of Business and Management defines Just in Time as a manufacturing system whose goal is to optimize processes by continuously pursuing waste reduction. Chase and Aquilano (1985) stated that Just In Time (JIT) requires the production department to project precisely the necessary units in the necessary quantities at the necessary time with the objectives of achieving plus or minus zero performance to schedule; it means that production of one extra piece is just as bad as being one piece short. Anything over the minimum amount necessary is viewed as waste. The idea of JIT is to drive all queues toward zero in order to minimize inventory investment, shorten production lead time, react faster to demand changes and uncover any quality problem. Barker (1989) opined that the JIT is a dynamic approach introduced in recent years that demand total commitment from management. Kaynak and Pagani (2003) stated that production and operations research has shown that JIT Purchasing can potentially have benefits to the firms in the form of increasing product quality, improving supplier/buyer relationships, and increasing sales. Akintoye (2004) stressed that the closeness of a company to the ideal JIT situation depends on the type of production process and the nature of suppliers industries. Inventory decisions are of interest to many functional and line managers in every organisation since these decisions may have direct impact on their departmental performance. Forgionne (1986) stressed that inventory policy involves resolving organizational conflicts since all departments connected with inventory in the organization have different views of what quantity of inventory to keep. Sound management should consider all view points and develop a policy that minimise total related inventory cost. Dominiak and Louderback (1997) in their contribution to the issue of conflict of functional department in respect of inventory levels to be maintained noted that sales managers, finance manager and production managers have different views on the desirable inventory level. This conflict of inventory objective is always resolved with great difficulty in a manufacturing environment. Brigham (1983) opined that proper inventory management require close coordination among the sales, purchasing, production and finance departments since improper co-ordination among the departments can lead to disaster and sub optimization. 
Good in inventory represents a cost to their owner. The manufacturer has the expense of materials and labour. "The wholesaler and retailer also have funds tied up". Therefore, the basic goal of the researchers is to maintain a level of inventory that will provide optimum stock at lowest cost. Morris (1995) stressed that inventory management in its broadest perspective is to keep the most economical amount of one kind of asset in order to facilitate an increase in the total value of all assets of the organization - human and material resources. Keth et al. (1994) in their text also stated that the major objective of inventory management and control is to inform managers how much of a good to reorder, when to re-order the good, how frequently orders should be placed and what the appropriate safety stock is, for minimizing stockouts. Thus, the overall goal of inventory is to have what is needed, and to minimize the number of times one is out of stock.

Drury (1996) defined inventory as a stock of goods that is maintained by a business in anticipation of some future demand. This definition was also supported by Schroeder (2000) who stressed that inventory management has an impact on all business functions, particularly operations, marketing, accounting, and finance. He established that there are three motives for holding inventories, which are transaction, precautionary and speculative motives. The transaction motive occurs when there is a need to holdstock to meet production and sales requirements.

A firm might also decide to hold additional amounts of stock to cover the possibility that it may have under estimated its future production and sales requirements. This represents a precautionary motive, which applies only when future demand is uncertain.

The speculative motive for holding inventory might entice a firm to purchase a larger quantity of materials than normal in anticipation of making abnormal profits. Advance purchase of raw materials in inflationary times is one form of speculative behavior.

\section{RESEARCH METHOD}

Generally, the search and gathering of facts/data and information for the advancement of knowledge is regarded as research. Research methodology therefore means the overall strategy designed to achieve the aim and objectives of the research. It includes the procedures and techniques of investigation for effective and reliable representation of the research. This chapter describes the procedures used in gathering the data needed to carry out this research work and the subsequent technique for processing and analyzing the collected data.

\section{Models APPLIED in InVEnTORY CONTROL SySTEM}

Model I: Derivation of Harris formula for instantaneous supply, continuous consumption and zero buffer stock

$Q=\sqrt{\frac{2 P . D}{H . C}}$

in this derivation, no reserve stock has been kept

$\mathrm{C}=$ unit cost

$\mathrm{D}=$ annual production or consumption

$\mathrm{P}=$ Procurement cost or preparation cost per order

$\mathrm{H}=$ inventory carrying rate or holding cost

Material cost $=$ unit cost $\mathrm{x}$ Annual Production or usage $=\mathrm{C} \times \mathrm{D}$

Annual inventory carrying cost or Holding Cost $=$ (holding cost $) \mathrm{x}$ average inventories

$=\frac{H Q}{2} C$

Preparation cost or setup cost $=$ preparation cost per unit $x D=\frac{P}{Q} D$

Total yearly cost (Total annual cost) $Y_{C}=$ Material cost + Holding cost + setup cost

$Y_{C}=C \cdot D+(H C) \frac{Q}{2}+\frac{P}{Q} D$ 
Model II: Economic Order Quantity or Economic lot size with reserved stock:

$Q=\sqrt{\frac{2 P . D}{H . C(1+2 f)}}$

Annual inventory carrying cost or Holding Cost $=($ holding cost $) \mathrm{x}$ average inventories $=H\left(R+\frac{Q}{2}\right) C$

Total yearly cost (Total annual cost) $Y_{c}=$ Material cost + Holding cost + setup cost

$Y_{C}=C \cdot D+H \cdot C\left(R+\frac{Q}{2}\right)+\frac{P}{Q} D$

Fraction of Q (f) $=\frac{R}{Q}$

$\mathrm{R}=$ Reserved stock and $\mathrm{Q}=$ Order Quantity or lot size

\section{Analyses and Results of the Experimental Data for Inventory Control SYSTEM}

The result of the experimental observation which was carried out on the inventory control system at G1 Company Enugu State, Nigeria as presented in tables 3, 7, 10 and 21. The data were presented on the monthly record of the inventory control system over the year. As stated earlier, inventory control system is stated as the process for managing and locating objects or materials. In common usage, the term may also refer to just the software components. Inventory Control is the forms and Models of Inventory Management. Inventories refer to those products or goods a firm is manufacturing for sale and components that make up the product.

Essentially, the primary source of data was from the company inventory records. Data were also gathered from direct observations from the manufacturing industry while the researcher was involved in daily production for a period of two months. The following tables showed the data collected:

\section{ANALYSIS AND RESULT}

Historical Inventory Data for 7 products in months, quartersand Years

Table1. Monthly Inventory Data in Plastic Pipe Company for 2012

\begin{tabular}{|c|c|c|c|c|c|c|c|}
\hline 总 & 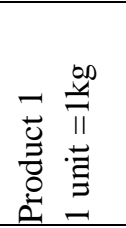 & 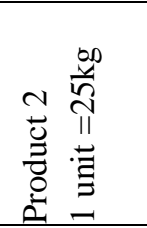 & 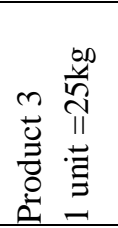 & 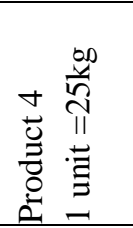 & 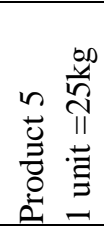 & 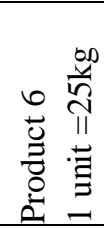 & 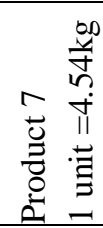 \\
\hline $\begin{array}{l}\text { Date } \\
(\mathrm{MM} / \mathrm{YY})\end{array}$ & Units & Units & Units & Units & Units & Units & Units \\
\hline Jan-2012 & 128047 & 4140.35 & 138.01 & 828.07 & 13.80 & 1.10 & .92 \\
\hline Feb-2012 & 214392 & 6932.27 & 231.08 & 1386.45 & 23.11 & 1.85 & 1.54 \\
\hline Mar-2012 & 196203 & 6344.14 & 211.47 & 1268.83 & 21.15 & 1.69 & 1.41 \\
\hline Apr-2012 & 347008 & 11220.35 & 374.01 & 2244.07 & 37.40 & 2.99 & 2.49 \\
\hline May-2012 & 141773 & 4584.16 & 152.81 & 916.83 & 15.28 & 1.22 & 1.02 \\
\hline Jun-2012 & 151660 & 4903.84 & 163.46 & 980.77 & 16.35 & 1.31 & 1.09 \\
\hline Jul-2012 & 198743 & 6426.27 & 214.21 & 1285.25 & 21.42 & 1.71 & 1.43 \\
\hline Aug-2012 & 137973 & 4461.30 & 148.71 & 892.26 & 14.87 & 1.19 & .99 \\
\hline Sep-2012 & 28162 & 910.61 & 30.35 & 182.12 & 3.04 & .24 & .20 \\
\hline Oct-2012 & 51432 & 1663.02 & 55.43 & 332.60 & 5.54 & .44 & .37 \\
\hline Nov-2012 & 112578 & 3640.15 & 121.34 & 728.03 & 12.13 & .97 & .81 \\
\hline Dec-2012 & 18353 & 593.44 & 19.78 & 118.69 & 1.98 & .16 & .13 \\
\hline
\end{tabular}

Source: Evepon Industries Limited 
Chinwuko Emmanuel Chuka et al.

Table2. Monthly Inventory Data in Plastic Pipe Company for 2013

\begin{tabular}{|c|c|c|c|c|c|c|c|}
\hline 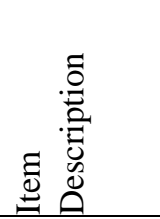 & 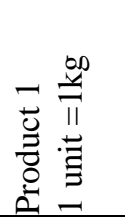 & 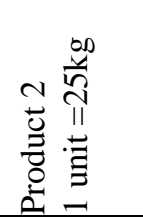 & 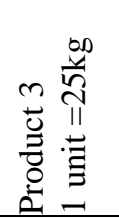 & 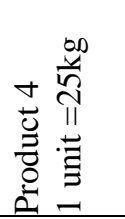 & 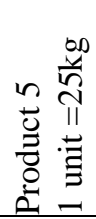 & 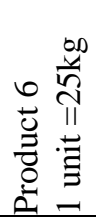 & 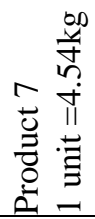 \\
\hline $\begin{array}{l}\text { Date } \\
(\mathrm{MM} / \mathrm{YY})\end{array}$ & Units & Units & Units & Units & Units & Units & Units \\
\hline Jan-2013 & 60103 & 1943.39 & 64.78 & 388.68 & 6.48 & .52 & .43 \\
\hline Feb-2013 & 47816 & 1546.11 & 51.54 & 309.22 & 5.15 & .41 & .34 \\
\hline Mar-2013 & 170542 & 5514.38 & 183.81 & 1102.88 & 18.38 & 1.47 & 1.23 \\
\hline Apr-2013 & 163722 & 5293.89 & 176.46 & 1058.78 & 17.65 & 1.41 & 1.18 \\
\hline May-2013 & 131343 & 4246.91 & 141.56 & 849.38 & 14.16 & 1.13 & .94 \\
\hline Jun-2013 & 142455 & 4606.22 & 153.54 & 921.24 & 15.35 & 1.23 & 1.02 \\
\hline Jul-2013 & 71699 & 2318.37 & 77.28 & 463.67 & 7.73 & .62 & .52 \\
\hline Aug-2013 & 102887 & 3326.82 & 110.89 & 665.36 & 11.09 & .89 & .74 \\
\hline Sep-2013 & 78700 & 2544.72 & 84.82 & 508.94 & 8.48 & .68 & .57 \\
\hline Oct-2013 & 61028 & 1973.32 & 65.78 & 394.66 & 6.58 & .53 & .44 \\
\hline Nov-2013 & 109894 & 3553.37 & 118.45 & 710.67 & 11.84 & .95 & .79 \\
\hline Dec-2013 & 153491 & 4963.08 & 165.44 & 992.62 & 16.54 & 1.32 & 1.10 \\
\hline
\end{tabular}

Source: Evepon Industries Limited

Table3. Monthly Inventory Data in Plastic Pipe Company for 2014

\begin{tabular}{|c|c|c|c|c|c|c|c|}
\hline 总 & 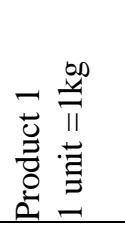 & 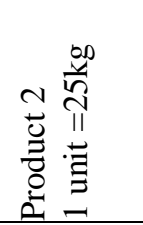 & 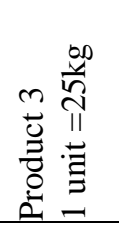 & 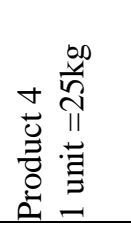 & 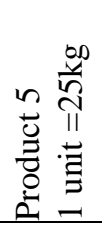 & 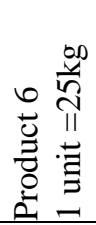 & 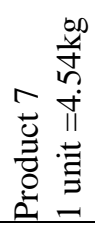 \\
\hline $\begin{array}{l}\text { Date } \\
(\mathrm{MM} / \mathrm{YY})\end{array}$ & Units & Units & Units & Units & Units & Units & Units \\
\hline Jan-2014 & 160944 & 5204.05 & 173.47 & 1040.81 & 17.35 & 1.39 & 1.16 \\
\hline Feb-2014 & 103584 & 3349.33 & 111.64 & 669.87 & 11.16 & .89 & .74 \\
\hline Mar-2014 & 112909 & 3650.85 & 121.70 & 730.17 & 12.17 & .97 & .81 \\
\hline Apr-2014 & 112913 & 3650.98 & 121.70 & 730.20 & 12.17 & .97 & .81 \\
\hline May-2014 & 171305 & 5539.06 & 184.64 & 1107.81 & 18.46 & 1.48 & 1.23 \\
\hline Jun-2014 & 215858 & 6979.67 & 232.66 & 1395.93 & 23.27 & 1.86 & 1.55 \\
\hline Jul-2014 & 146227 & 4728.20 & 157.61 & 945.64 & 15.76 & 1.26 & 1.05 \\
\hline Aug-2014 & 147808 & 4779.29 & 159.31 & 955.86 & 15.93 & 1.27 & 1.06 \\
\hline Sep-2014 & 72697 & 2350.61 & 78.35 & 470.12 & 7.84 & .63 & .52 \\
\hline Oct-2014 & 172304 & 5571.36 & 185.71 & 1114.27 & 18.57 & 1.49 & 1.24 \\
\hline Nov-2014 & 32896 & 1063.67 & 35.46 & 212.73 & 3.55 & .28 & .24 \\
\hline Dec-2014 & 89872 & 2905.97 & 96.87 & 581.19 & 9.69 & .77 & .65 \\
\hline
\end{tabular}

Source: Evepon Industries Limited

Table4. Unit Cost of the Inventory Products

\begin{tabular}{|l|l|}
\hline Inventory Products & Unit cost \\
\hline $32 \mathrm{~mm}$ Extrution plastic Pipe & $\mathrm{N} 250$ \\
\hline PVC & $\mathrm{N} 22,500$ \\
\hline Stabilizer & $\mathrm{N} 16,534$ \\
\hline Calcium & $\mathrm{N} 5,597$ \\
\hline Steric acid & $\mathrm{N} 17,000$ \\
\hline Titanium & $\mathrm{N} 33,600$ \\
\hline Pigments & $\mathrm{N} 7,260$ \\
\hline
\end{tabular}

Source: Evepon Industries Limited

Product 2= PVC, Product 3= stabilizer, Product 4=Calcium, Product 5=Steric Acid, Product 6=Titanium and Product 7= Pigments 
Evaluation and Optimization of Inventory Control Systems in Small and Medium Scale Industries

\section{Modeling ANd Analysis of DATA}

Results of the Inventory System in the Case study

Table5. The Results of the Inventory System in the CaseStudy Plastic Manufacturing Company

\begin{tabular}{|l|l|l|l|l|l|l|}
\hline Inventory Products & PVC & Stabilizer & Calcium & Steric Acid & Titanium & Pigments \\
\hline unit Holding Cost & 32 & 65 & 46 & 189 & 570 & 762 \\
\hline Unit Cost & 9500 & 6530 & 5590 & 8700 & 3600 & 7260 \\
\hline Unit Setup Cost & 2375 & 1632.5 & 1397.5 & 2175 & 900 & 1815 \\
\hline Yearly Average & 49141.17 & 1638.04 & 9828.23 & 163.8 & 13.1 & 10.92 \\
\hline Economic Order Quantity & 2700.81 & 286.84 & 772.77 & 61.4 & 6.43 & 7.21 \\
\hline $\begin{array}{l}\text { Average Economic Order } \\
\text { Quantity per Year }\end{array}$ & 1350.41 & 143.42 & 386.38 & 30.7 & 3.22 & 3.61 \\
\hline Annual Holding Cost & 43213.01 & 9322.46 & 17773.69 & 5802.4 & 1833.37 & 2748 \\
\hline Annual Setup Cost & 43213.01 & 9322.46 & 17773.69 & 5802.4 & 1833.37 & 2748 \\
\hline Length of Order Cycle per Year & 0.05 & 0.18 & 0.08 & 0.37 & 0.49 & 0.66 \\
\hline $\begin{array}{l}\text { Length of Order Cycle within } \\
\text { Days/ Days it takes to achieve } \\
\text { EOQ }\end{array}$ & 16.49 & 52.53 & 23.59 & 112.45 & 147.27 & 198.14 \\
\hline $\begin{array}{l}\text { Number of orders placed in a } \\
\text { year (n)=(D/C) }\end{array}$ & 5.1728 & 0.2508 & 1.7582 & 0.0188 & 0.0036 & 0.0015 \\
\hline & & & & & & \\
\hline Number =(D/Q) & 1551.83 & 75.25 & 527.45 & 5.65 & 1.09 & 0.45 \\
\hline Lead Time & 18.19 & 5.71 & 12.72 & 2.67 & 2.04 & 1.51 \\
\hline Reordering point & 4.12 & 13.13 & 5.9 & 28.11 & 36.82 & 49.54 \\
\hline Consumption Rate & 675.2 & 71.71 & 193.19 & 15.35 & 1.61 & 1.8 \\
\hline
\end{tabular}

Variables of the EOQ

D: The demand in quantity per unit time. Demand can be thought of as a rate.

Q: The order quantity. This is the variable we want to optimize. All the other variables are fixed quantities.

$\boldsymbol{S}:$ The order cost. This is the flat fee charged for making any order and is independent of $\boldsymbol{Q}$.

H: Holding (carrying) cost per unit time.

C: Unit cost

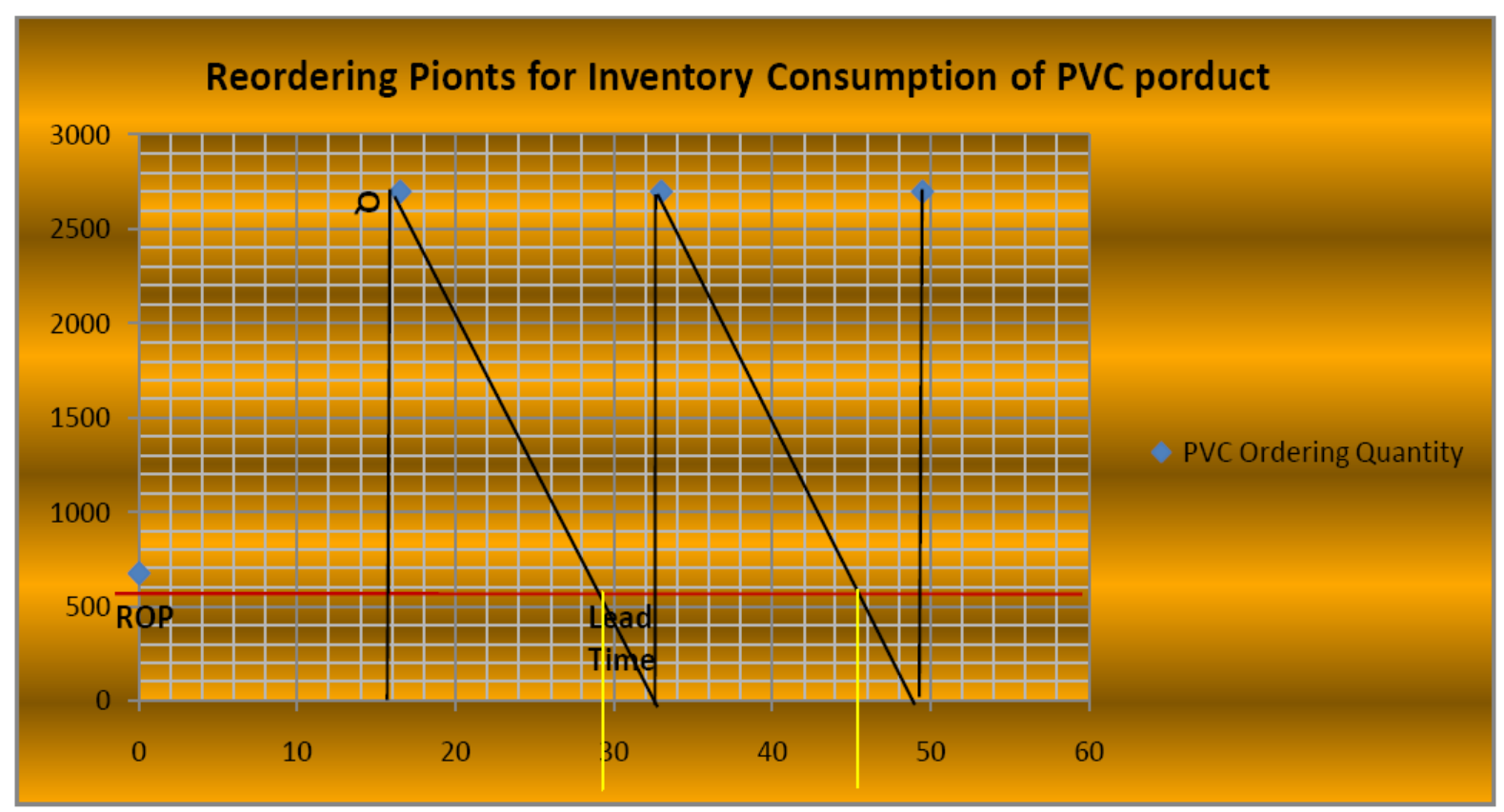

Figure1. The Profile of Inventory Cycle Level over Time in PVC Product 
Chinwuko Emmanuel Chuka et al.

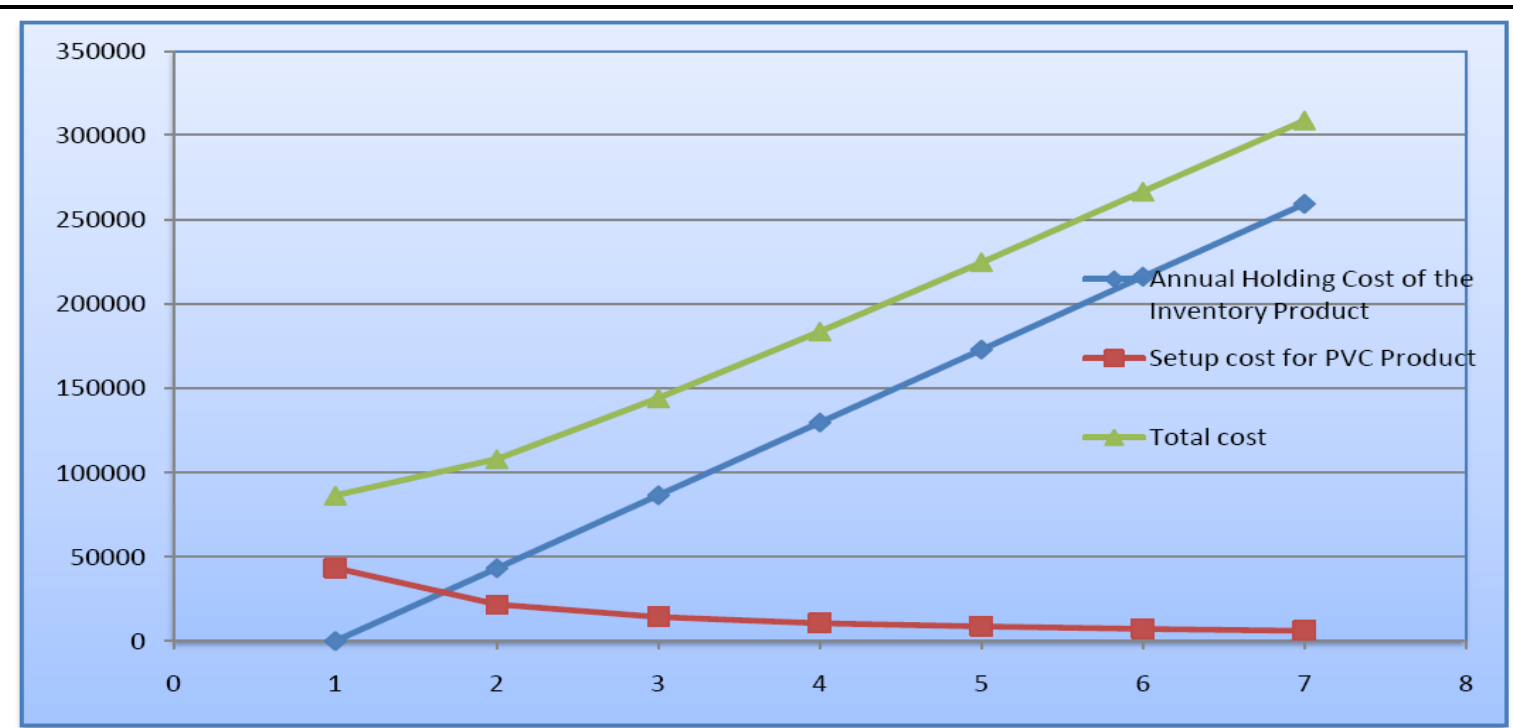

Figure2. The Profile of Total Cost for PVC Raw Material in Stock

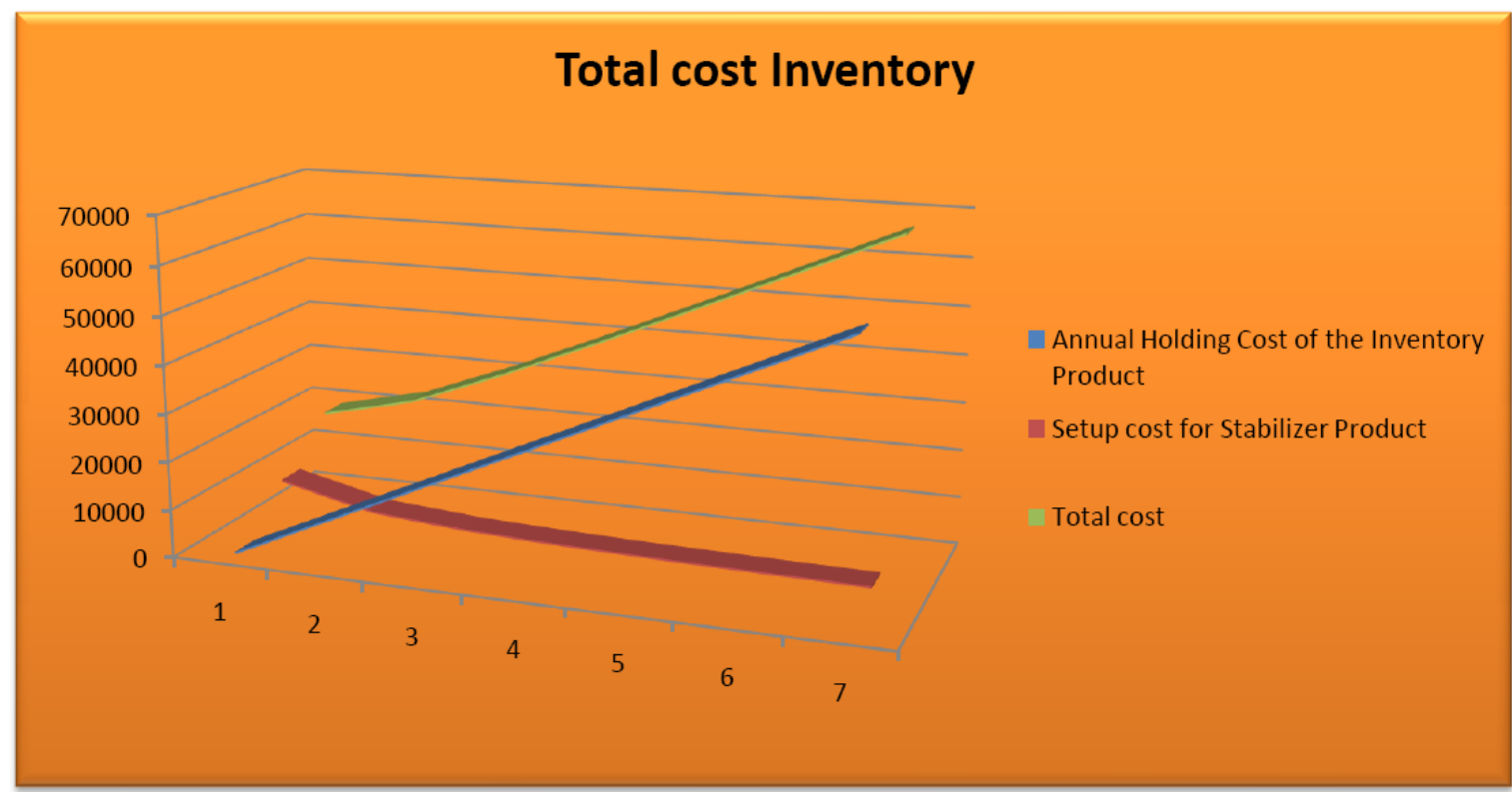

Figure3. The total cost of inventory level for Stabilizer Raw Material in Stock

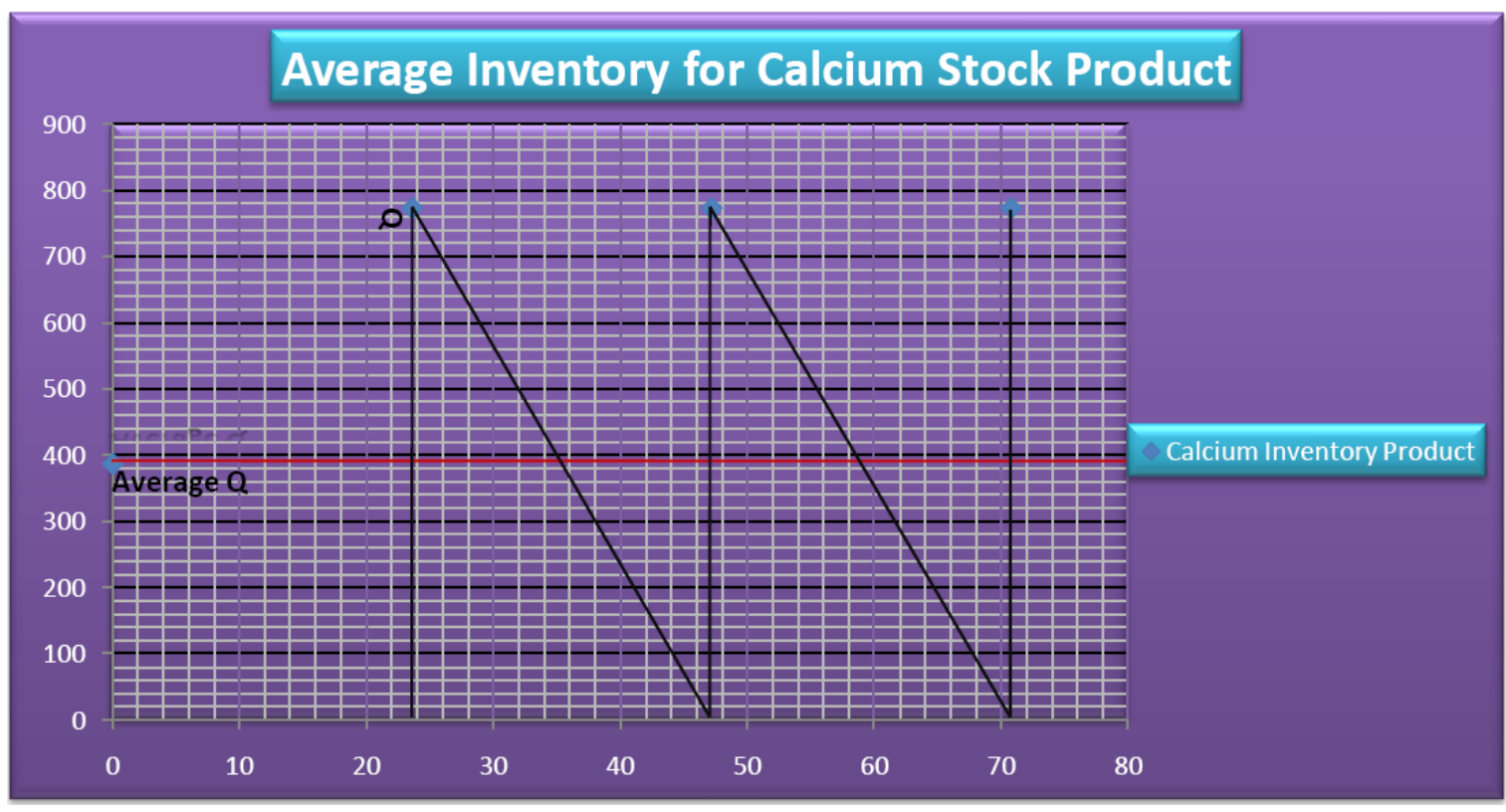

Figure4. The Average Inventory Level for Calcium Raw Material in Stock 
Evaluation and Optimization of Inventory Control Systems in Small and Medium Scale Industries

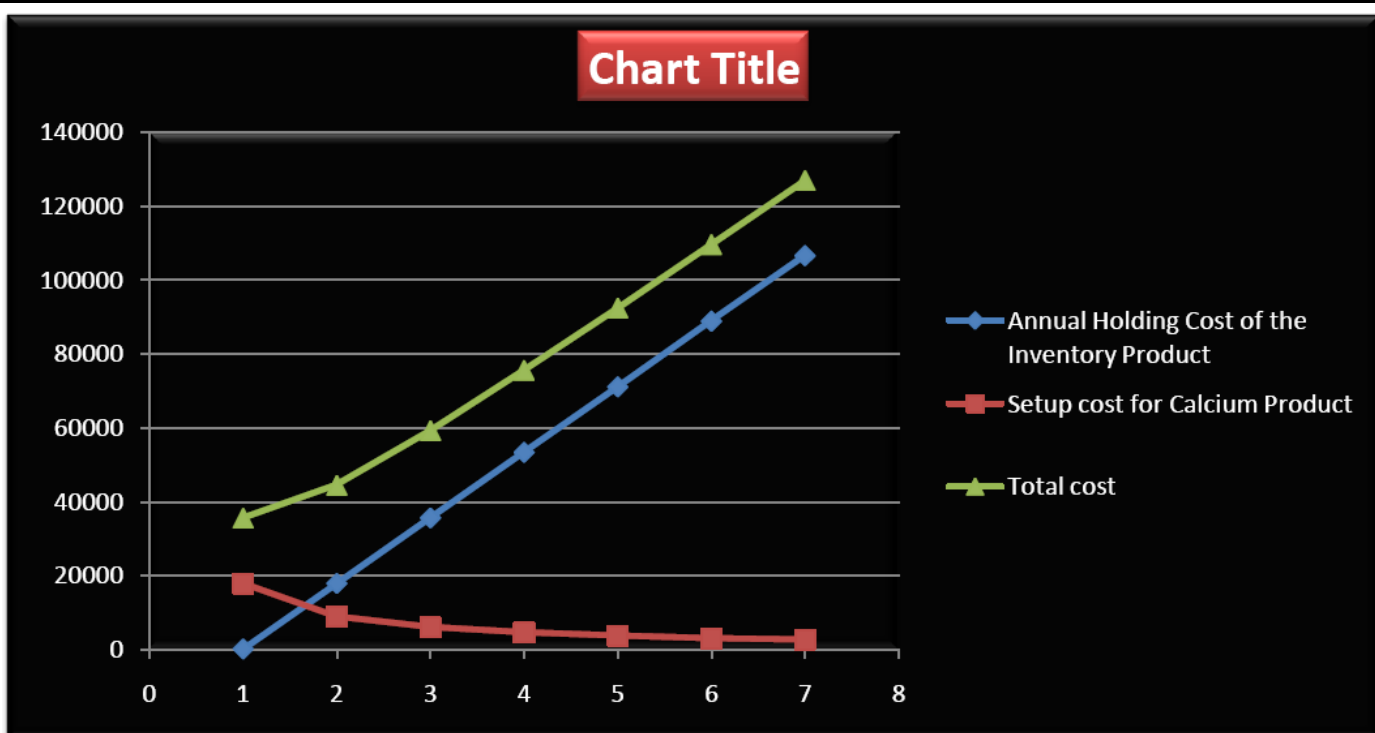

Figure5. The total cost of inventory level for Calcium Raw Material in Stock

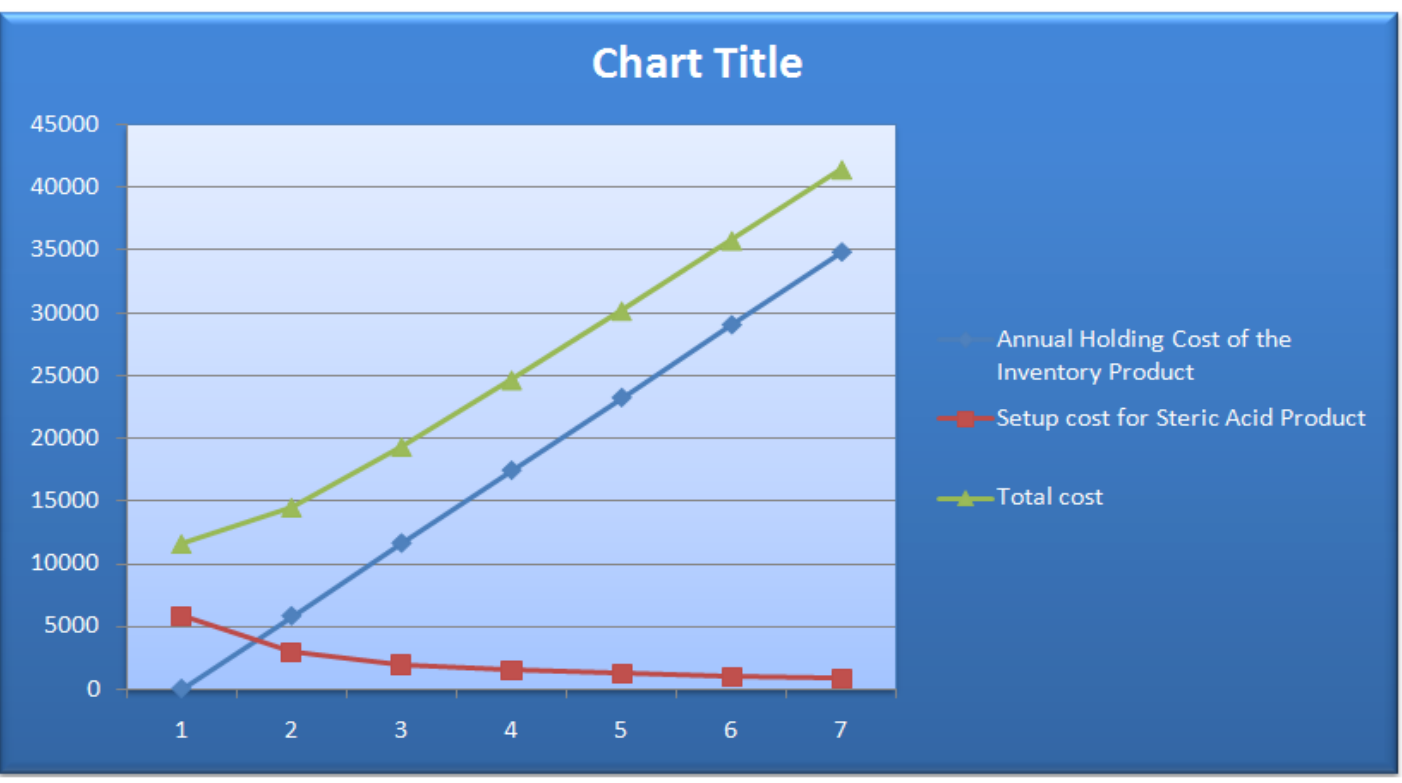

Figure6. The total cost of inventory level for Steric Acid Raw Material in Stock

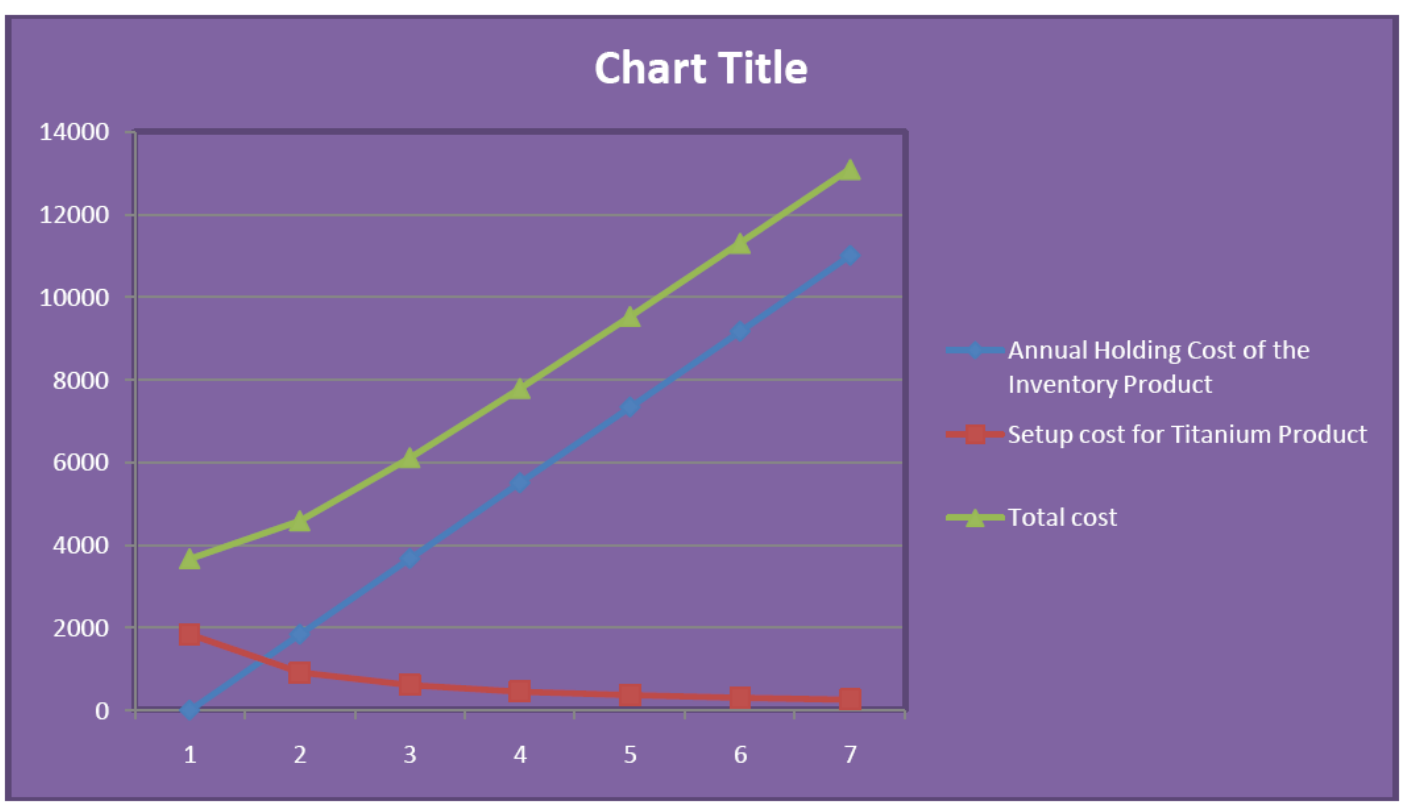

Figure7. The total cost of inventory level for Titanium Raw Material in Stock 


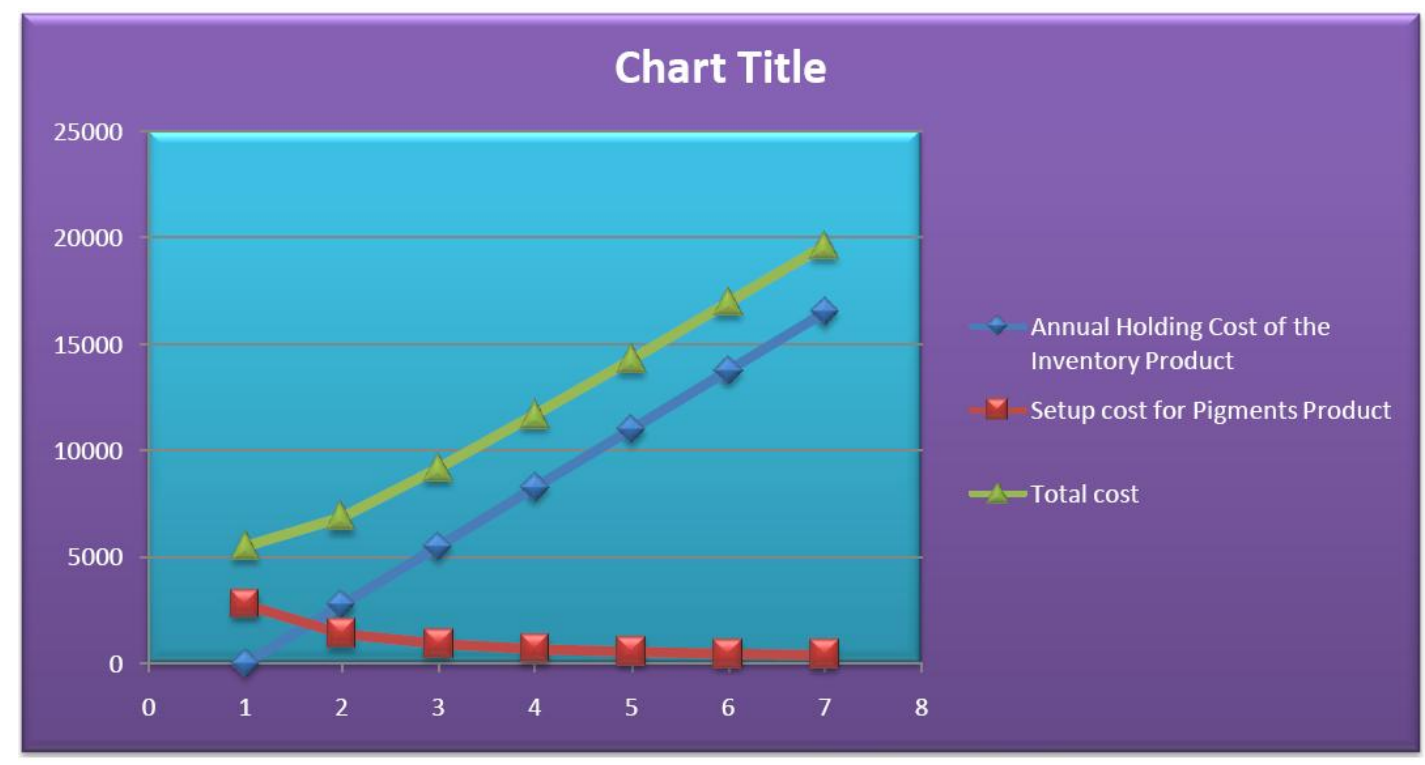

Figure8. The total cost of inventory level for Pigments Raw Material in Stock

Table6. ABC Analysis in Inventory Stock

\begin{tabular}{|l|l|l|l|}
\hline ABC Analysis & Inventory Item(s) & Average Inventory & Percentage Inventory \\
\hline A & PVC & 0.808306 & $80.83 \%$ \\
\hline B & Calcium & 0.161661 & $16.17 \%$ \\
\hline C & $\begin{array}{l}\text { Stabilizer, Steric acid, Titanium and } \\
\text { Pigments }\end{array}$ & 0.030033 & $3 \%$ \\
\hline
\end{tabular}

\section{Discussion OF THE RESUltS}

Existing inventory control models were applied to evaluate the inventory control system and the economic production quantity of the case study company. In the aforementioned company, the researcher studied the inventory control system of their extrusion plastic production and the inventory of the plastic raw materials. The raw materials studied in the company are; PVC, stabilizer, Pigments, Calcium, Titanium and Steric Acid. Furthermore, the researcher also studies the economic production of the extrusion plastic pipe product.

However, the inventory control system models were applied in each of the raw materials and the results were explained as follows.

The study of the inventory shows that one unit of PVC raw material in inventory stock is equivalent to one bag of PVC and is also equivalent to twenty five kilograms $(25 \mathrm{~kg})$ of PVC raw material product. The application of the inventory control models show that the economic ordering quantity of the PVC product is 2700.81 units, also the average economic order quantityof the PVC product is 1350.41 units, while the Length of ordering cycle within days or days it takes to achieve economic ordering quantity (EOQ) is 16.49 days (i.e. sixteen (16) days, twelve (12) hours sixteen (16) minutes). However, the annual holding cost or annual carrying cost of the product is 43213.01 , while the annual ordering cost or setup cost of the product is 43213.01 . The unit cost (i.e. $25 \mathrm{~kg}$ ) of the product is 9500 , while the unit setup cost and the unit holding cost of the raw material product are 2375and 32 respectively. However, the reordering point of the product is at 675.2 units while the lead time of the product is 4.12 days ( 4 days, 2 hours 53 minutes). Furthermore, the consumption rate of the raw material is 163.8 units per day.

The study of the inventory shows that one unit of stabilizer raw material in inventory stock is equivalent to one bag of stabilizer and is also equivalent to twenty five kilograms $(25 \mathrm{~kg})$ of stabilizer raw material product. The application of the inventory control models show that the economic ordering quantity of the stabilizer product is 286.84 units, also the average economic order quantityof the stabilizer product is 143.42 units, while the Length of ordering cycle within days or days it takes to achieve economic ordering quantity (EOQ) is 52.53 days (i.e. fifty two (52) days, thirteen (13) hours, twelve (12) minutes). However, the annual holding cost or annual carrying cost of the product is 9322.46, while the annual ordering cost or setup cost of the product is 9322.46. The unit cost (i.e. $25 \mathrm{~kg}$ ) of the product is 6530 , while the unit setup cost and the unit holding cost of the raw material 
product are 1632.5 and 65 respectively. However, the reordering point of the product is at 71.71 units while the lead time of the product is 13.13 days (13 days, 3 hours 12 minutes). Furthermore, the consumption rate of the raw material is 5.46 units per day.

The study of the inventory shows that one unit of Calcium raw material in inventory stock is equivalent to one bag of Calcium and is also equivalent to twenty five kilograms $(25 \mathrm{~kg})$ of Calcium raw material product. The application of the inventory control models show that the economic ordering quantity of the Calcium product is 772.77 units, also the average economic order quantityof the Calcium product is 386.38 units, while the Length of ordering cycle within days or days it takes to achieve economic ordering quantity (EOQ) is 23.59 days (i.e. twenty three (23) days, thirteen (14) hours, ten (10) minutes). However, the annual holding cost or annual carrying cost of the product is 17773.69, while the annual ordering cost or setup cost of the product is 17773.69. The unit cost (i.e. $25 \mathrm{~kg}$ ) of the product is 5590, while the unit setup cost and the unit holding cost of the raw material product are 1397.5 and 46 respectively. However, the reordering point of the product is at 193.19 units while the lead time of the product is 5.9 days (5 days, 2 hours 10 minutes). Furthermore, the consumption rate of the raw material is 32.76 units per day.

The inventory result shows that one unit of Steric Acid in stock is equivalent to one bag of Steric Acid and is also equivalent to twenty five kilograms $(25 \mathrm{~kg})$ of Steric Acid raw material product. The application of the inventory control models show that the economic ordering quantity of the Steric Acid product is 61.4 units, also the average economic order quantityof the Steric Acid product is 30.7 units, while the Length of ordering cycle within days or days it takes to achieve economic ordering quantity (EOQ) is 112.45 days (i.e. one hundred and twelve (112) days, ten (10) hours, forty eight (48) minutes). However, the annual holding cost or annual carrying cost of the product is 5802.4, while the annual ordering cost or setup cost of the product is 5802.4 . The unit cost (i.e. $25 \mathrm{~kg}$ ) of the product is 8700 , while the unit setup cost and the unit holding cost of the raw material product are 2175 and 189 respectively. However, the reordering point of the product is at 15.35 units while the lead time of the product is 28.11 days ( 28 days, 2 hours 38 minutes). Furthermore, the consumption rate of the raw material is 0.55 unit per day.

The inventory result shows that one unit of Titanium in stock is equivalent to one bag of Titanium and is also equivalent to twenty five kilograms $(25 \mathrm{~kg})$ of Titanium raw material product. The application of the inventory control models show that the economic ordering quantity of the Titanium product is 6.43 units, also the average economic order quantityof the Titanium product is 3.22 units, while the Length of ordering cycle within days or days it takes to achieve economic ordering quantity (EOQ) is 147.27 days (i.e. one hundred and forty seven (147) days, six (6) hours, twenty nine (29) minutes). However, the annual holding cost or annual carrying cost of the product is 1833.37 , while the annual ordering cost or setup cost of the product is 1833.37 . The unit cost (i.e. $25 \mathrm{~kg}$ ) of the product is 3600 , while the unit setup cost and the unit holding cost of the raw material product are 900 and 570 respectively. However, the reordering point of the product is at 1.61 units while the lead time of the product is 36.82 days ( 36 days, 19 hours 41 minutes). Furthermore, the consumption rate of the raw material is 0.044 units per day.

The study of the inventory shows that one unit of Pigments raw material in inventory stock is equivalent to one bag of Pigments and is also equivalent to twenty five kilograms $(15 \mathrm{~kg})$ of Pigments raw material product. The application of the inventory control models show that the economic ordering quantity of the Pigments product is 7.21 units, also the average economic order quantityof the Pigments product is 3.61 units, while the Length of ordering cycle within days or days it takes to achieve economic ordering quantity (EOQ) is 198.14 days (i.e. twenty three (23) days, thirteen (14) hours, ten (10) minutes). However, the annual holding cost or annual carrying cost of the product is 2748 , while the annual ordering cost or setup cost of the product is 2748 . The unit cost (i.e. $15 \mathrm{~kg}$ ) of the product is 7260, while the unit setup cost and the unit holding cost of the raw material product are 1815 and 762 respectively. However, the reordering point of the product is at 1.8 units while the lead time of the product is 49.54 days ( 5 days, 2 hours 10 minutes). Furthermore, the consumption rate of the raw material is 0.036 units per day.

The ABC inventory analysis shows that PVC raw material has about $80.83 \%$ of the inventory, Calcium raw material has about $16.17 \%$ inventory, while steric acid, Titanium, Stabilizer and Pigments has about 3\% of the inventory raw materials in stock. However, the results have created standards to the case study company in particular and to other companies that adopt the inventory control system. 


\section{CONCLUSION}

In conclusion, the researcher studied the inventory control system of plastic pipes and its raw materials in the case study company. The application of the existing inventory control models was adopted to establish the economic ordering quantity for the raw material and economic production quantity for the produced plastic pipes. The raw materials; PVC, stabilizer, Calcium, Steric acid, Titanium and Pigments show the economic ordering quantity of 2700.81, 286.84, 772.77, 61.4, 6.43 and 7.21 respectively while the plastic pipe product shows the economic production quantity of 3318.56. The researcher also establish the Length of ordering cycle within days or days it takes to achieve the economic ordering quantity for the raw materials; PVC, stabilizer, Calcium, Steric acid, Titanium and Pigments to be 675.2, 71.71, 193.19, 15.35, 1.61 and 1.8 respectively, while the Length of production cycle within days is 0.77 days (i.e. 18 hours, 28 minutes 20 seconds per day). Furthermore, the lead time for the inventory raw materials: PVC, stabilizer, Calcium, Steric acid, Titanium and Pigments are 4.12, 13.13, 5.9, 28.11, 36.82 and 49.54 respectively while the lead time for plastic pipe production is 4 hours 37 minutes 20 seconds per day. The ABC inventory analysis shows that PVC raw material has about $80.83 \%$ of the inventory, Calcium raw material has about $16.17 \%$ inventory, while steric acid, Titanium, Stabilizer and Pigments has about 3\% of the inventory raw materials in stock. The application of this inventory control models and tools help the researcher to establish a standard for the case study company in particular and any manufacturing company that has inventory system. This system will help to resolve the inventory control problems in establishment.

\section{REFERENCES}

Adeyemi, S. L. and SalamiA.O.(2007) Inventory Management: A Tool of Optimizing Resources in a Manufacturing Industry: A Case Study of Coca-Cola Bottling Company, Ilorin Plant. Department of Business Administration, University of Ilorin.Department of Management cience, LadokeAkintola University of Technology, Ogbomoso.

Akintoye, I.R. (2004): Investment Decisions: Concepts, Analysis and Management. Glorious Hope Publishers.

Lagos. p 370

Barker, T. (1989): The Essential of Material Management. McGraw Hill Book Co. London. p 261

Brigham, E.F. (1983): Fundamentals of Financial Management: The Dryden Publishers, Tokyo. p 549.

Chase, R.B. andAquilano, N.J. (1985): Production and Operations Management. 4thEdition, IRWIN Homewood.Illinios.pp 470-483,533

Dimitrios P. Koumanakos (2004) The effect of inventory management on firm performance: Industrial Management and Information Systems Laboratory, Department of Mechanical Engineering and Aeronautics, University of Patras, Rio, Greece

Dominiak, G.E. and LouderBack, J.G. (1997): Managerial Accounting, 8th Edition.: South Western CollegePublishing, Cincinate Ohio. p 258

Drury, C.,(1996). Management and Cost Accounting. London: International Housan Business Press

Edwardson, W. (1989): Improvement of the Small Scale Food Industry Developing Countries. UNIDO IndustryDevelopment, No. 27 p13

Forgionne, G.A. (1986): Quantitative Decision Making. Woodsworth Publishing Company. Balmont Califonia.p 660

Frederick H. Abernathy, (2014): A Stitch in Time: Lean Retailing and the Transformation of Manufacturing

Garrison, R.H. and Noreen, E.W .(2000): Managerial Accounting. Ninth Edition. Irwin McGraw Hill, NewYork p 407

Jegede, J.F.S. (1992): Stock Control for Cost Control. The Nigerian Accountant Journal October/ December1992 Vol. 25 No. 4 p 34.

Kaynak, H. and Pagani, R.A. (2003): Just In Time Purchasing and Technical Efficiency in the US

Keth, L., Muhlemen, A., Oakland,J., (1994). Production and Operations Management. London: Pitman Publisher. 
Kotler P. (2002) Marketing Management 2nd Edition, The Millenium Edition. New Delhi, Prentice Hall,India

Loveman,G and Sengenberger, W (1992): Economic and Social Reorganisation In the Small and Medium Enterprises Sector in Senegenberger W. Loveman G. and Piore M.J. (eds.) The Reemergence of SmallEnterprises: Industrial Restructuring in Industrialised Countries International Institute for Labour Studies, Geneva. p 43

Morris C 1995. Quantitative Approach in Business Studies: London: Pitman Publisher. Nigeria Bottling Company. 2004. Annual Report.

Ogunleye, G.A. (2000): Small and Medium Scale Enterprises as Foundation for Rapid Economic Development in Nigeria. NDIC Quarterly Journal Vol. 10 December, 2000 N0 4. p 23

Orlicky, J. (1975): Material Requirement Planning: McGraw-Hill , New York . p 158.

Pandey, I. M. (2005): Financial Management. Enlarged Edition,: Vikas Publishing House Ltd. New Delhi p.904

Plane, D.R. (1994): Management Science - A Spread Sheet Approach Boys and Fraser Publishing Company. Danvers Massachetts p.245

Rosenblatt, B.S.,(1977). Modern Business- A Systems Approach. 2nd Edition, Boston: Houghton MifflinCo.

Schreibfeder, J. (2001): Varying the Carrying Cost for Individual Product. Effective Inventory Management Inc.South Denton.http//www. effectiveinventoryCom/articles.htm Down loaded on 7th October, 2007

Schroeder, R.G.,(2000). Operations Management- Contemporary Concepts and Cases. USA: InternationalEdition. Manufacturing Sector International Journal of Production Research Vol.41 No 1 pp 1-14

\section{AUTHORS BiOgRAPHY}

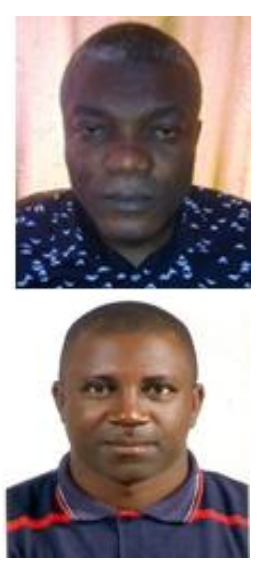

I am Engr. Dr. Chinwuko Emmanuel Chuka, a senior Lecturer and Head of Department in Industrial and Production Engineering NnamdiAzikiwe University, Awka, Anambra State, Nigeria.

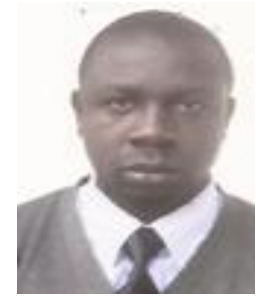

Asowo Clement Sunday, is a postgraduate student of Industrial \& Production Department, Nnamdi Azikiwe University, awka, Anambra state, Nigeria. I am a professional Engineer with about four years working experience in the Mechanical Engineering Laboratory, Standards Organisation of Nigeria (SON), Enugu, and Enugu-State. 